\title{
4. Inhibiting in function of Gene in sickle Cell Disease
}

\author{
Dr. Akshay Nandeshwar, Assistant Professor, \\ Dept of Sharir Rachana, VPAMC, Sangli.
}

\section{Chapter 1: Introduction Research Question:}

Can Ayurvedic medicines cure Sickle-Cell Disease? If it does, then to what extent and at what rate they cure the disease?

\subsection{Introduction:}

I was much struck with the fact that SickleCell Disease and most of the genetic diseases are incurable. The knowledge I gained about base substitution mutation in DNA and the Human Genome Project, showed me light to the possibility of a cure to the disease. Stem Cell Therapy was the first thing that came into my mind, while thinking of a cure to SCD. Eventually I found that researches about using stem cell therapy for curing SCD were already being carried in various academic and research institutions across the globe. As a result, bone marrow transplant became a ray of hope for the sufferers of the disorder; but still, the scientists and doctors would assert the non-existence of a definite cure to the disease.

\subsection{What is Sickle Cell Disease?}

Sickle-Cell Disease (SCD), or sickle-cell anaemia (SCA) or drepanocytosis is one of the most life-threatening diseases ever discovered. The disease not only disturbs the life of the patients but also his family. As there has been no definite treatment or cure for the disease till date, the patients are very frequently admitted in hospitals and have to undergo unbearable pain. Some forms of Sickle-Cell Disease tell us that it is even more fatal than Cancer and AIDS. In spite of being a very deadly and widespread disorder in many parts of the country, Government of India has not taken any serious steps regarding eliminating or researching on the treatment and cure of SCD. This collection of clinical findings was unknown until the explanation of sickle cells was given by Chicago cardiologist and professor of medicine James B. Herrick. The disease was named "sickle-cell anaemia" by Vernon Mason in 1922.

Sickle cell disease has struck millions of people across the globe and is predominantly widespread among those whose ancestors are from sub-Saharan Africa, Spanish-speaking regions in the Western Hemisphere (South America, the Caribbean, and Central America), Saudi Arabia, India, and Mediterranean countries such as Turkey, Greece, and Italy. ${ }^{1}$ It affects an estimated 70,000 to 100,000 Americans. The disease occurs in about 1 out of every 500 African Americans births, and about 1 out of every 36,000 Hispanic Americans births. The trait of SCD occurs in about 1 in 12 African Americans. ${ }^{2}$ Sickle cell disease is a major public health concern. From 1989 through 1993, there was an average of 75,000 hospitalizations due to sickle cell disease in the United States, costing approximately $\$ 475$ million. During 2005, medical expenditures, in the US, for children with sickle cell disease averaged $\$ 11,702$ for children with Medicaid coverage and \$14,772 for children with employer-sponsored insurance. Sickle cell-related death among African-American children less than 4 years of age fell by $42 \%$ during 1999 to 2002. This coincides with the introduction of a vaccine that protected against invasive pneumococcal disease in 2000. The disease can be found in people living in parts of the world where malaria is or was common. It is believed that people who carry the sickle cell trait are less likely to catch malaria.

Sickle cell anaemia is an inherited form of anaemia - a condition in which there aren't enough fit red blood cells to carry sufficient

\footnotetext{
${ }^{1} \mathrm{CDC}$

${ }^{2} \mathrm{NHLBI}$
} 
oxygen throughout the body. In normal condition, the red blood cells have biconcave shape and are flexible. They can move easily through the blood vessels. Whereas, in sickle cell anaemia and other forms of SCD, the red blood cells become rigid, sticky and are shaped like sickles or crescent moons. These irregularly shaped cells can get stuck in small blood vessels, which can slow or block blood flow and oxygen to parts of the body. There's no cure for most people with sickle cell anaemia. However, treatments can relieve pain and help prevent further problems associated with sickle cell anaemia. ${ }^{3}$

\section{Theoretical Basis:}

Sickle cell anaemia is a genetic disorder which is inherited from parents to the offspring. It has been known to be caused by mutations in the DNA of the RBCs. Mutation is any event that changes genetic structure; any alteration in the inherited nucleic acid sequence of the genotype of an organism. ${ }^{4}$

A mutation can just involve one nucleotide or it can even have an effect on a huge segment of the gene. It is often thought that a mutation which involves a smaller number of nitrogenous bases in the DNA will be less significant than one where a larger number of bases are changed. In the gene that controls sickle-cell anaemia a alteration of just one base lead to a protein with one amino acid distorted and the resulting disease. Haemoglobin is made of four polypeptide chains: two alpha chains and two beta chains. When an $\mathrm{A}$ to $\mathrm{T}$ base substitution occurs in the region of the gene coding for the 6th amino acid in the beta chain, the codon GAG (glutamic acid) becomes GTG (valine).

The resulting polypeptide is different and the haemoglobin formed is commonly known as $\mathrm{HbS}$; the normal' haemoglobin is known as $\mathrm{HbA}$. The result of this is a slightly different structure, by one amino acid of the

\footnotetext{
${ }^{3} \mathrm{CDC}$

${ }^{4}$ Wordweb
}

haemoglobin molecule which makes it crystallise at low oxygen levels (e.g. in the capillaries). The erythrocyte in which the haemoglobin can be found will then change from a biconcave shape into a sickle-cell shape (see Figure 404) and can block the small capillaries, and is less efficient at transporting oxygen. Even when the oxygen concentration increases again, the cells keep their sickle shape. The symptoms of sickle-cell anaemia are acute anaemia, which causes physical weakness. The lack of oxygen may be severe enough to cause damage to the heart and kidneys or even death (in homozygous individuals). The gene for sickle-cell anaemia is co-dominant with the "normal" allele although the latter is expressed more strongly in the heterozygous individual. Heterozygous individuals (carriers) have some $\mathrm{HbS}$ but more normal haemoglobin. They may suffer from mild anaemia. The selective advantage of being a carrier is found in malaria infested areas. Plasmodium (the protist causing malaria) cannot reproduce in erythrocytes with $\mathrm{HbS}$. This means that individuals heterozygous for the sickle-cell trait have a reduced chance of contracting malaria. Natural selection has ensured that the sickle-cell trait is more common among people living in malariainfested areas such as West Africa. As the African-American population largely originates from this area, the trait is found in frequencies higher than usual in this group. Carriers may not be aware of the fact that they possess the sickle-cell allele and are capable of passing it on to their children. If two carriers have a child, there is a 1 in $4(25 \%)$ chance of the child having the disease.

Therefore, it is important that people who may be carriers, are tested to confirm the presence or absence of the sickle cell allele. If a female carrier is pregnant and the father is also a carrier, it is possible to test using amniocentesis or chorionic villi sampling (refer to Topic 4.2.6) to see if the child will have sickle-cell anemia. Should this be the case, then the parents may decide to discontinue the 
pregnancy. There are no easy answers to this

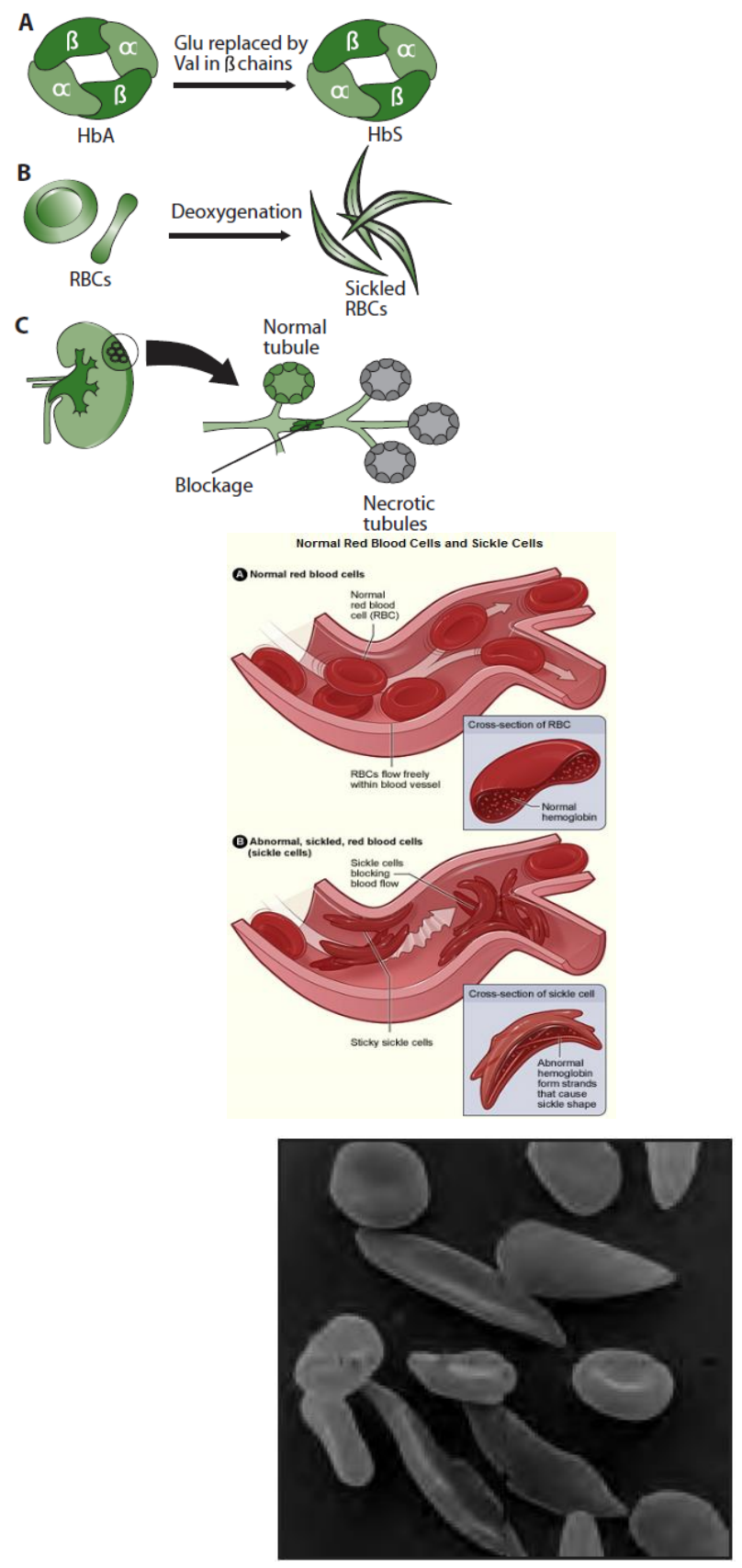

about treating sickle-cell anemia including bone marrow transplant and/or blood stem cell treatment. Gene therapy is also a possibility but research is in an early stage. ${ }^{5}$

Symptoms: problem. A great deal of research is being done

Signs and symptoms of sickle cell anaemia usually show up after an infant is 4 months old and may include:

1. Anaemia: Sickle cells are fragile. They break apart easily and die, leaving you chronically short on red blood cells. Red blood cells usually live for about 120 days before they die and need to be replaced. However, sickle cells die after only 10 to 20 days. The result is a chronic shortage of red blood cells, known as anaemia. Without enough red blood cells in circulation, your body can't get the oxygen it needs to feel energized. That's why anaemia causes fatigue.

2. Episodes of pain: Periodic episodes of pain, called crises, are a major symptom of sickle cell anaemia. Pain develops when sickleshaped red blood cells block blood flow through tiny blood vessels to your chest, abdomen and joints. Pain can also occur in your bones. The pain may vary in intensity and can last for a few hours to a few weeks. Some people experience only a few episodes of pain. Others experience a dozen or more crises a year. If a crisis is severe enough, you may need hospitalization so that pain medication can be injected into your veins (intravenously).

3. Hand-foot syndrome: Swollen hands and feet may be the first signs of sickle cell anaemia in babies. The swelling is caused by sickle-shaped red blood cells blocking blood flow out of their hands and feet.

4. Jaundice: Jaundice is a yellowing of the skin and eyes that occurs because of liver damage or dysfunction. Occasionally, people who have sickle cell anaemia have some degree of jaundice because the liver, which filters harmful substances from the blood, is overwhelmed by the rapid breakdown of red blood cells. In people with dark skin, jaundice is visible mostly as yellowing of the whites of the eyes. 
5. Frequent infections: Sickle cells can damage your spleen, an organ that fights infection. This may make you more vulnerable to infections. Doctors commonly give infants and children with sickle cell anaemia antibiotics to prevent potentially lifethreatening infections, such as pneumonia.

6. Delayed growth: Red blood cells provide your body with the oxygen and nutrients you need for growth. A shortage of healthy red blood cells can slow growth in infants and children and delay puberty in teenagers.

7. Vision problems: Some people with sickle cell anaemia experience vision problems. Tiny blood vessels that supply your eyes may become plugged with sickle cells. This can damage the retina - the portion of the eye that processes visual images. $^{6}$

\section{Ayurveda:}

Ayurveda is the oldest surviving complete medical system in the world. Derived from its ancient Sanskrit roots - 'ayus' (life) and 'ved' (knowledge) - and offering a rich, comprehensive outlook to a healthy life, its origins go back nearly 5000 years. It was expounded and practiced by the same spiritual rishis, who laid the foundations of the Vedic civilisation in India, by organising the fundamentals of life into proper systems. Ayurveda offers a unique blend of science and philosophy that balances the physical, mental, emotional and spiritual components necessary for holistic health.

\section{General Observations about the treatment:}

It was observed that after about 1 year of this treatment the patients stopped having blood transfusion as their haemoglobin level was rising. The crisis of the patients has also reduced during the first year of the treatment drastically. The patients reported to be fully cured from the basic problems cause by SCD such as join pain, fever and weakness.

\section{Chapter 2: Methodology}

\subsection{Objectives of study:}

1. To verify if the Ayurvedic medicines composed of plant extracts cure Sickle-Cell Disease.

2. To investigate the extent to which the Ayurvedic medicines cure SCD.

3. To find out the rate at which they cure SCD.

\subsection{HYPOTHESIS}

HYPOTHESIS 1: The Ayurvedic medicines to a large extent help cure SCD.

HYPOTHESIS 2: All the symptoms which are directly related to abnormality in shape of RBCs will be cured.

HYPOTHESIS 3: The medicines will show evident effects on the shape of RBCs in a year.

\section{Survey:}

20 patients who have been undergoing treatment since 1 year at the clinic were surveyed about the prognosis of their health problems. The following were the results:

\begin{tabular}{|l|l|}
\hline Symptoms & $\begin{array}{l}\text { Cured or } \\
\text { not }\end{array}$ \\
\hline $\begin{array}{l}\text { Chronic shortage of RBCs } \\
\text { (Anaemia) }\end{array}$ & \\
\hline Episodes of pain/crisis & \\
\hline Hand-foot syndrome & \\
\hline Jaundice & \\
\hline
\end{tabular}

\begin{tabular}{|l|l|}
\hline Complication & $\begin{array}{c}\text { Cured or } \\
\text { not }\end{array}$ \\
\hline Strokes & \\
\hline Acute chest syndrome & \\
\hline Pulmonary hypertension & \\
\hline Organ damage & \\
\hline Blindness & \\
\hline Skin ulcers & \\
\hline
\end{tabular}




\section{Gallstones}

\section{Questionnaire:}

Q. 1 How long have you been undergoing ayurvedic treatment of Dr. Nandeshwar?
a. Less than a year
b. 1 year
c. More than a year

Q2. Which of the following symptoms did you have before undergoing the treatment?
a. Anaemia
b. Pain/crisis
c. Hand-foot syndrome
d. Jaundice

Q3. How effectively have your symptoms (specified) subsidised?
a. Completely
b. Somewhat
c. Almost completely
d. Not at all

\section{Final Experiment:}

To verify why the symptoms subsided in SCD cases, an experiment was conducted. In the experiment I planned to use the blood samples of 10 different patients, which were collected by Doctor Ashay Nandeshwar collected of 10 patients at a regular interval of 2 months.

\subsection{Variables:}

\begin{tabular}{|c|c|c|}
\hline \multicolumn{2}{|c|}{ Dependent Variables (DV) } & $\begin{array}{l}\text { - } \\
\text { sample. } \\
\text { - } \quad \text { Number of defected cells in the sample. } \\
\text { - } \quad \text { Number of normal cells in the sample }\end{array}$ \\
\hline \multirow{2}{*}{$\begin{array}{c}\text { Controlled } \\
\text { Variables }\end{array}$} & $\begin{array}{l}\text { Independent } \\
\text { Variables } \\
\text { (IV) }\end{array}$ & $\begin{array}{l}\bullet \quad \text { Amount of blood used to prepare each } \\
\text { slide. }\end{array}$ \\
\hline & $\begin{array}{l}\text { Fixed Variables } \\
\text { (Constants) }\end{array}$ & $\begin{array}{l}\text { Number of blood cells in the sample } \\
\text { over a period of time }\end{array}$ \\
\hline \multicolumn{2}{|c|}{ Uncontrolled Variables } & 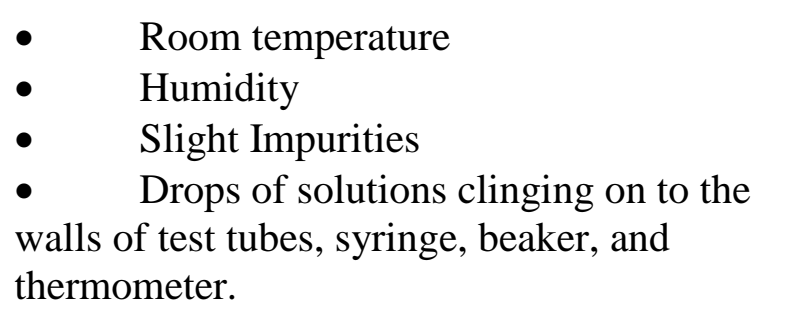 \\
\hline
\end{tabular}

\section{$\underline{\text { Materials: }}$}

- $\quad$ Slides

- Droppers

- Leishman stain

- $\quad$ Distilled water

- $\quad$ Syringe with needles

- Cotton

- $\quad$ Spirit

\section{Procedure 1: Preparing the blood smears}

1. Distilled water was used to clean all the slides. The slides were then kept open to dry 2. $5 \mathrm{ml}$ syringes were used to take out blood from the patients. In adult patients, the blood was taken out from a vein in the arm; and in young children the blood was taken from finger tips. 


\section{Ayurlog: National Journal of Research in Ayurved Science}

A Web based quarterly online published peer reviewed National E-journal of Ayurveda.

3. About $0.5 \mathrm{ml}$ of blood was taken out from each patient.

4. Each blood sample was then added into a test-tube (cleaned and dried).

5. Separate droppers were used to transfer 1 drop of blood from each sample from the test-tubes to the slides.

6. The slides were then covered with Leishman stain, and were then allowed to dry for about 30 minutes each.
Procedure 2: Viewing the smears under a microscope and counting the cells

1. The prepared slides were then viewed under an optical microscope.

2. A digital camera was used to capture the images from the eye-piece.

3. The digital images were then zoomed on a computer and then counted.

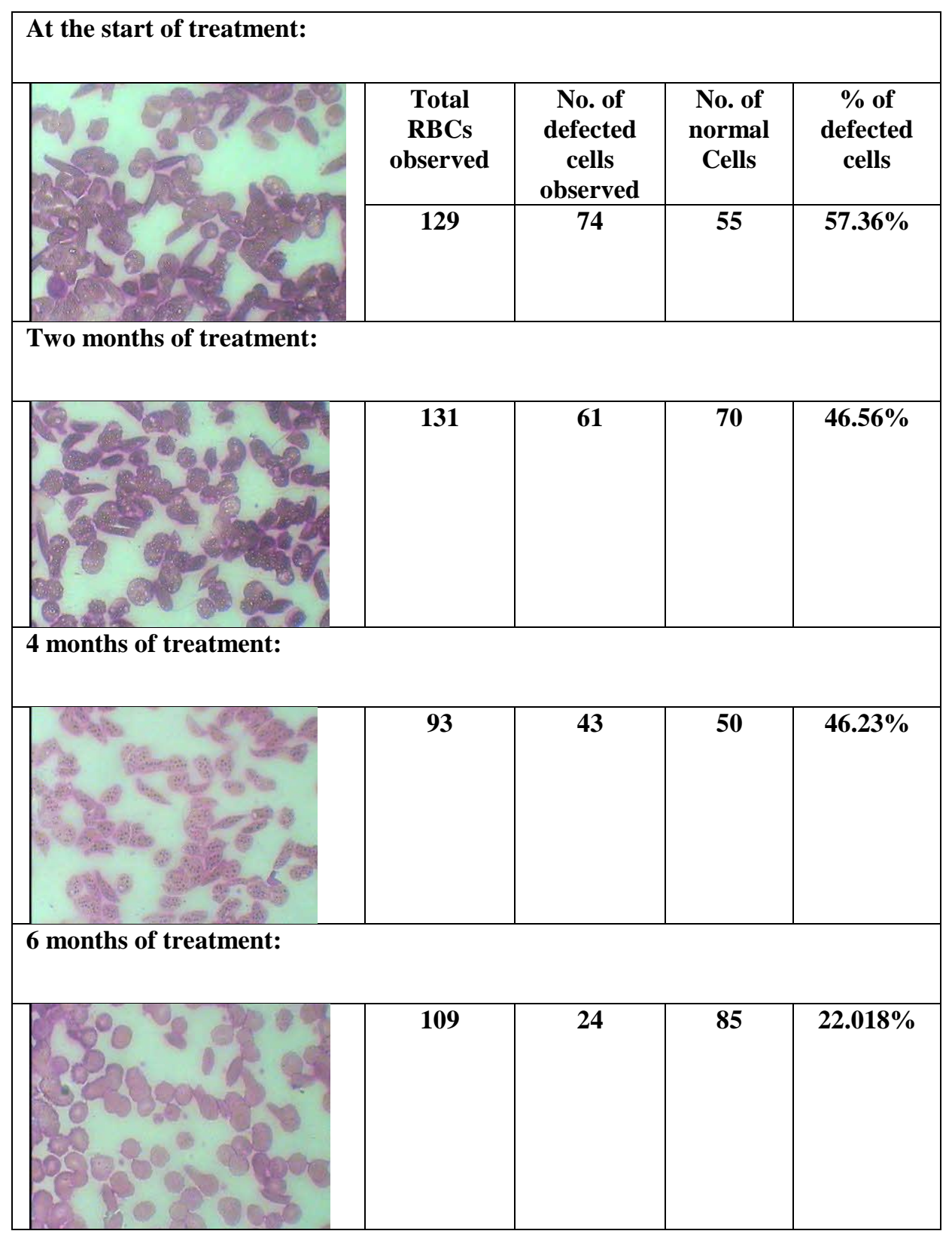


Ayurlog: National Journal of Research in Ayurved Science

A Web based quarterly online published peer reviewed National E-journal of Ayurveda.

8 months of treatment:

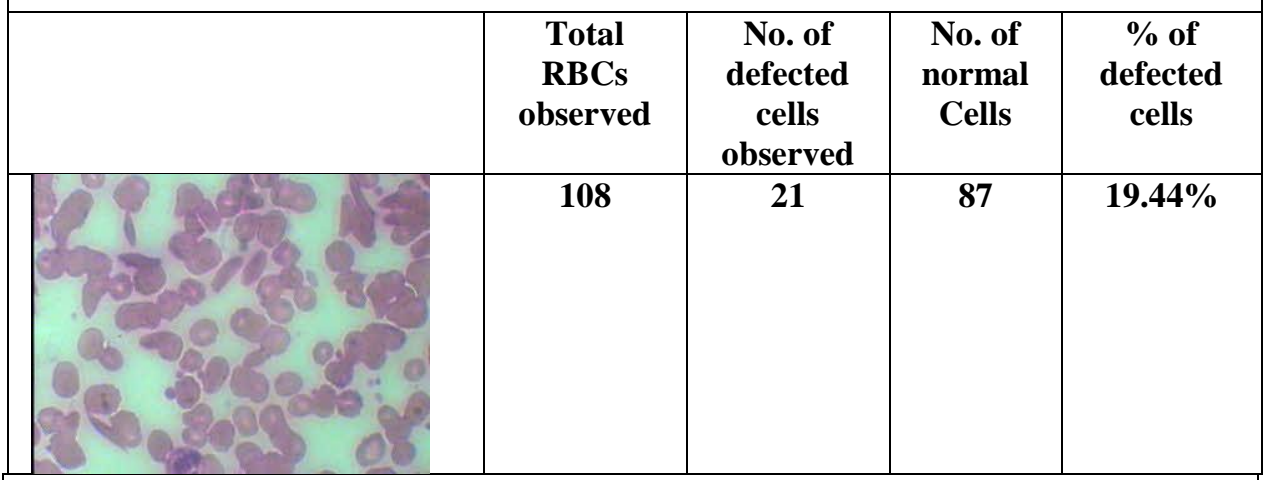

\begin{tabular}{|l|l|l|l|l|}
\hline 10 months of treatment: & 128 & 15 & 113 & $11.71 \%$ \\
\hline 12 months of treatment: & & & \\
\hline
\end{tabular}
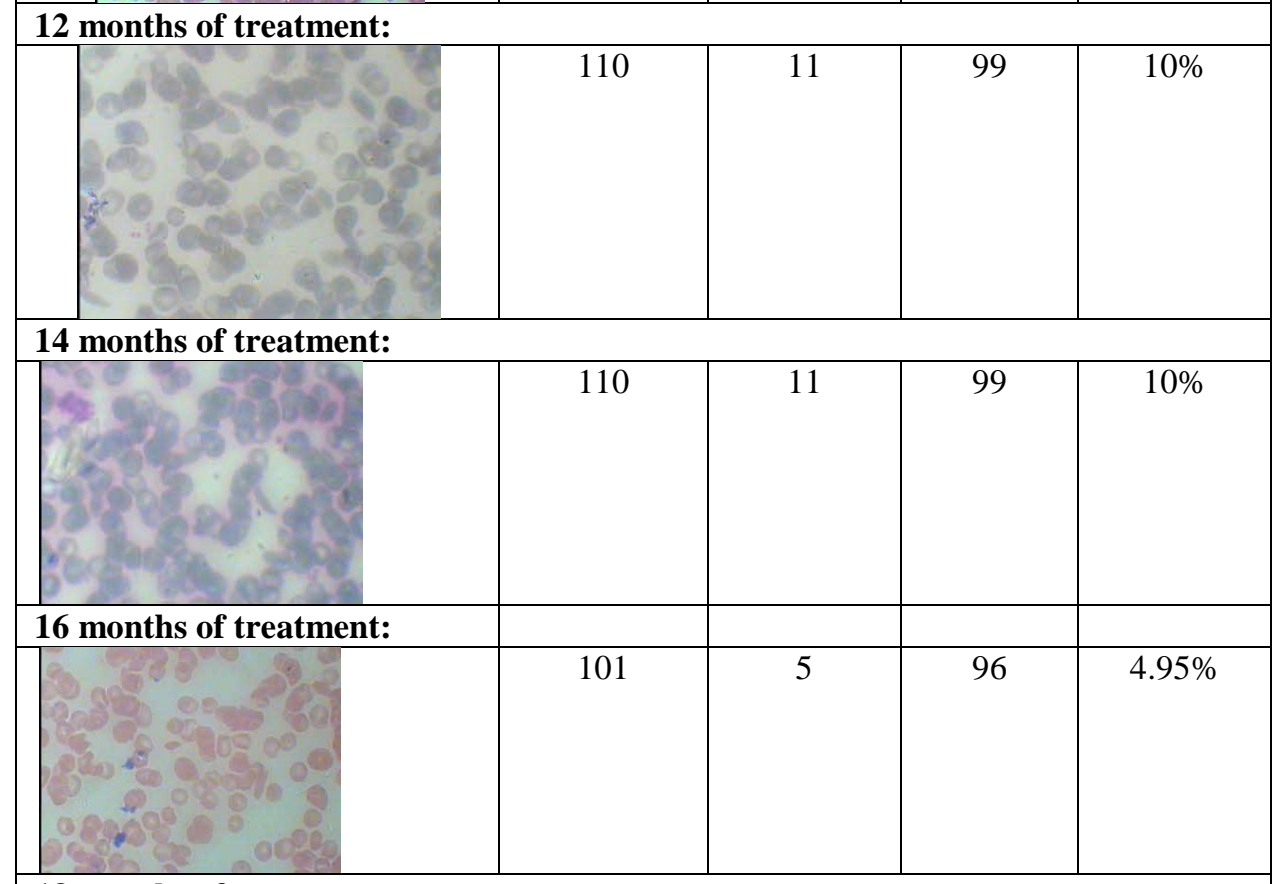

18 months of treatment:

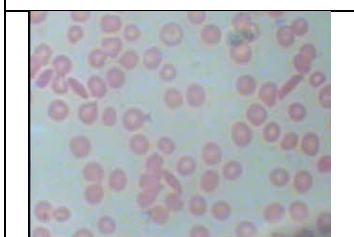

87

4

83

$4.59 \%$ 
Ayurlog: National Journal of Research in Ayurved Science

A Web based quarterly online published peer reviewed National E-journal of Ayurveda.

\begin{tabular}{|l|c|c|c|c|}
\hline 20 months of treatment: \\
\hline & $\begin{array}{c}\text { Total } \\
\text { RBCs } \\
\text { observed }\end{array}$ & $\begin{array}{c}\text { No. of } \\
\text { defected } \\
\text { cells } \\
\text { observed }\end{array}$ & $\begin{array}{c}\text { No. of } \\
\text { normal } \\
\text { Cells }\end{array}$ & $\begin{array}{c}\text { \% of } \\
\text { defected } \\
\text { cells }\end{array}$ \\
\hline & 133 & 2 & 131 & $1.50 \%$ \\
\hline 22 months of treatment: & & & & \\
\hline & 134 & 1 & 133 & $0.74 \%$ \\
\hline & & & & \\
\hline
\end{tabular}

Statistical Analysis:
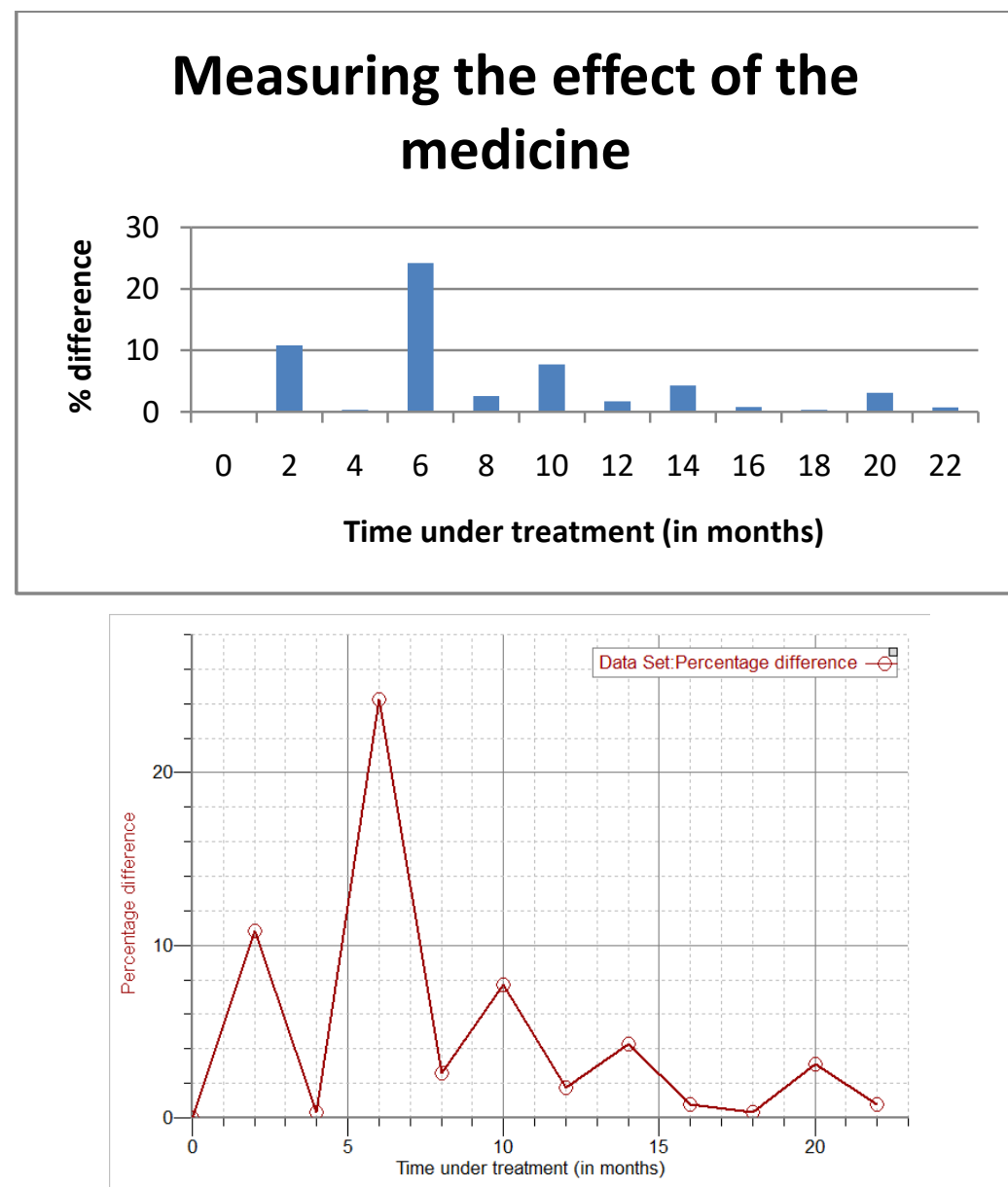
No apparent trend can be observed in the above statistics.

\section{Limitations and Scope for Improvement:}

\section{Improvements in the procedure:}

1. Before using them the slides should be washed with an acid, then rinsed in distilled water and then air-dried. This is done to make the slides free of alkaline substances if the cells are going to adhere.

2. The slide should be made as soon as possible after the cells have been taken from the patient and collected in ethylenediaminetetraacetic acid (EDTA). If you wait too long, the cells will lose their shape and the true shape is extremely important for diagnosing. This was a very big limitation in the experiment.

3. The blood cells were not properly spread out in the above slides. This is was a very significant limitation of the experiment. Due to the over-lapping of the blood cells some there definitely must have been an error in counting. To overcome this limitation a thin capillary tube should have been used to take out the blood sample on to the slide.

4. The Science Advisory Board has laid down specific protocols for preparing blood smears. According to the protocol the procedure should include the use of Smear Fix $(\subseteq$ on the wet preparation or the slide gently into a coplin jar of acetic alcohol (3\% acetic acid in $95 \%$ methanol). These two solutions are fixative which helps to keep the blood cells stable.

\section{Complications}

Sickle cell anaemia can lead to a host of complications, including:

* Stroke. A stroke can occur if sickle cells block blood flow to an area of your brain. Stroke is one of the most serious complications of sickle cell anemia. Signs of stroke include seizures, weakness or numbness of your arms and legs, sudden speech difficulties, and loss of consciousness. If your baby or child has any of these signs and symptoms, seek medical treatment immediately. A stroke can be fatal.
* Acute chest syndrome. This lifethreatening complication of sickle cell anaemia causes chest pain, fever and difficulty breathing. Acute chest syndrome can be caused by a lung infection or by sickle cells blocking blood vessels in your lungs. It requires emergency medical treatment with antibiotics, blood transfusions and drugs that open up airways in your lungs. Recurrent attacks can damage your lungs.

* Pulmonary hypertension. About one-third of people with sickle cell anemia will eventually develop high blood pressure in their lungs (pulmonary hypertension). Shortness of breath and difficulty breathing are common symptoms of this condition, which can ultimately lead to heart failure.

* Organ damage. Sickle cells can block blood flow through blood vessels, immediately depriving an organ of blood and oxygen. In sickle cell anemia, blood is also chronically low on oxygen. Chronic deprivation of oxygenrich blood can damage nerves and organs in your body, including your kidneys, liver and spleen. Organ damage can be fatal.

* Blindness. Tiny blood vessels that supply your eyes can get blocked by sickle cells. Over time, this can damage the retina - the portion of the eye that processes visual images - and lead to blindness.

* Skin ulcers. Sickle cell anaemia can cause open sores, called ulcers, on your legs.

* Gallstones. The breakdown of red blood cells produces a substance called bilirubin. Bilirubin is responsible for yellowing of the skin and eyes (jaundice) in people with sickle cell anemia. A high level of bilirubin in your body can also lead to gallstones.

* Priapism. Men with sickle cell anaemia may experience painful erections, a condition called priapism. As occurs in other parts of the body, sickle cells can block the blood vessels in the penis. This can damage the penis and eventually lead to impotence.

Tests and diagnosis 


\section{Ayurlog: National Journal of Research in Ayurved Science \\ A Web based quarterly online published peer reviewed National E-journal of Ayurveda.}

A blood test can check for hemoglobin S - the defective form of hemoglobin that underlies sickle cell anemia. In the United States, this blood test is part of routine newborn screening done at the hospital. But older children and adults can be tested too.

In adults, a blood sample is drawn from a vein in the arm. In young children and babies, the blood sample is usually collected from a finger or heel. The sample is then sent to a laboratory, where it's screened for hemoglobin S.

If the screening test is negative, there is no sickle cell gene present. If the screening test is positive, further tests will be done to determine whether one or two sickle cell genes are present. People who have one gene - sickle cell trait - have a fairly small percentage of hemoglobin S. People with two genes - sickle cell disease - have a much larger percentage of the defective hemoglobin.

\section{Treatments and drugs}

Bone marrow transplant offers the only potential cure for sickle cell anemia. But, finding a donor is difficult and the procedure has serious risks associated with it, including death.

As a result, treatment for sickle cell anemia is usually aimed at avoiding crises, relieving symptoms and preventing complications. If you have sickle cell anemia, you'll need to make regular visits to your doctor to check your red blood cell count and monitor your health. Treatments may include medications to reduce pain and prevent complications, blood transfusions and supplemental oxygen, as well as bone marrow transplant.

\section{Medications}

Medications used to treat sickle cell anemia include:

* Antibiotics. Children with sickle cell anemia usually begin taking the antibiotic penicillin when they're about 2 months of age and continue taking it until they're 5 years old. Doing so helps prevent infections, such as pneumonia, which can be life-threatening to an infant or child with sickle cell anemia. Antibiotics may also help adults with sickle cell anemia fight certain infections.

* Pain-relieving medications. To relieve pain during a sickle crisis, your doctor may advise over-the-counter pain relievers and application of heat to the affected area. You may also need stronger prescription pain medication.

* Hydroxyurea (Droxia, Hydrea). This prescription drug, normally used to treat cancer, may be helpful for adults with severe disease. When taken daily, it reduces the frequency of painful crises and may reduce the need for blood transfusions. It seems to work by stimulating production of fetal hemoglobin - a type of hemoglobin found in newborns that helps prevent the formation of sickle cells. There is some concern about the possibility that long-term use of this drug may cause tumors or leukemia in certain people. Your doctor can help you determine if this drug may be beneficial for you.

Assessing stroke risk

Using a special ultrasound machine (transcranial), doctors can learn which children have a higher risk of stroke. This test can be used on children as young as 2 , and those who are found to have a high risk of stroke are then treated with regular blood transfusions.

Blood transfusions

In a red blood cell transfusion, red blood cells are removed from a supply of donated blood. These donated cells are then given intravenously to a person with sickle cell anemia.

Blood transfusions increase the number of normal red blood cells in circulation, helping to relieve anemia. In children with sickle cell anemia at high risk of stroke, regular blood transfusions can decrease their risk of stroke.

Blood transfusions carry some risk. Blood contains iron. Regular blood transfusions cause an excess amount of iron to build up in your body. Because excess iron can damage your heart, liver and other organs, people who undergo regular transfusions must often receive 


\section{Ayurlog: National Journal of Research in Ayurved Science \\ A Web based quarterly online published peer reviewed National E-journal of Ayurveda.}

treatment to reduce iron levels. Deferasirox (Exjade) is an oral medication that can reduce excess iron levels. It can be used in people older than 2.

\section{Supplemental oxygen}

Breathing supplemental oxygen through a breathing mask adds oxygen to your blood and helps you breathe easier. It may be helpful if you have acute chest syndrome or a sickle cell crisis.

\section{Bone marrow transplant}

This procedure replaces bone marrow affected by sickle cell anemia with healthy bone marrow from a donor who doesn't have the disease. It can be a cure, but the procedure is risky, and it's difficult to find suitable donors. Researchers are still studying bone marrow transplants for people with sickle cell anemia. Currently, the procedure is recommended only for people who have significant symptoms and problems from sickle cell anemia.

Bone marrow transplant requires a lengthy hospital stay. After the transplant, you'll need drugs to help prevent rejection of the donated marrow.

\section{Treating complications}

Doctors treat most complications of sickle cell anemia as they occur. Treatment may include antibiotics, vitamins, blood transfusions, painrelieving medicines, other medications and possibly surgery, such as to correct vision problems or to remove a damaged spleen.
Experimental treatments

Scientists continue to gain new insights into the symptoms and causes of sickle cell anemia. Some possible new treatments being studied include:

* Gene therapy. Because sickle cell anemia is caused by a defective gene, researchers are exploring whether inserting a normal gene into the bone marrow of people with sickle cell anemia will result in the production of normal hemoglobin. Scientists are also exploring the possibility of turning off the defective gene while reactivating another gene responsible for the production of fetal hemoglobin - a type of hemoglobin found in newborns that prevents sickle cells from forming.

* Butyric acid. Normally used as a food additive, butyric acid may increase the amount of fetal hemoglobin in the blood.

* Clotrimazole. This over-the-counter antifungal medication helps prevent a loss of water from red blood cells, which may reduce the number of sickle cells that form.

* Nitric oxide. Sickle cell anemia causes low levels of nitric oxide, a gas that helps keep blood vessels open and reduces the stickiness of red blood cells. Treatment with nitric oxide may prevent sickle cells from clumping together.

* Nicosan. This is an herbal treatment in early trials in the U.S. Nicosan has been used to prevent sickle crises in Nigeria. 